\section{Left Main Coronary Dissection in Takayasu's Arteritis: the Value of Transesophageal Echocardiography and Intravenous Ultrasonography}

\author{
Emre YALÇINKAYA, ${ }^{1}$ Barış BUGAN, ${ }^{2}$ Murat ÇELİK ${ }^{1}$ \\ ${ }^{1}$ Department of Cardiology, Aksaz Military Hospital, Muğla, Turkey \\ ${ }^{2}$ Department of Cardiology, Girne Military Hospital, Girne, Cyprus \\ ${ }^{3}$ Department of Cardiology, Gülhane Military Medical Faculty, \\ Ankara, Turkey
}

We read with interest the article by Akpinar et al. ${ }^{1}$ entitled "Left Main Coronary Dissection in a Patient with Takayasu's Arteritis" that was published in the Turkish Journal of Rheumatology.

The authors ${ }^{1}$ reported on a 48-year-old female patient who was diagnosed with Takayasu's arteritis along with a spontaneous left main coronary artery dissection. After the dissection was identified by coronary angiography, the patient was referred for emergency coronary artery bypass surgery.

Takayasu's arteritis is a chronic inflammatory process that primarily involves the aorta and its main branches. Because 10-30\% of Takayasu's arteritis patients have coronary artery lesions, this disease should be regarded as a risk factor for aortic dissection and aneurysm. ${ }^{2}$

In this case, the authors performed transthoracic echocardiography to rule out aortic dissection, involving the arch and coronary ostial narrowing before and during surgery. In previous studies, the sensitivity and specificity were $59.3 \%$ and $76.9 \%$, respectively for transthoracic echocardiography and $98-100 \%$ and 95-98\%, respectively for transesophageal echocardiography in the diagnosis of aortic dissection. ${ }^{3,4}$

We believe that transesophageal echocardiography is an extremely useful tool, and it is now used widely for the detection of aortic diseases ${ }^{5}$ because the entire thoracic aorta and left main coronary ostium can be viewed, and any aortic regurgitation can be easily seen.

Furthermore, the characteristics of coronary lesions can affect which particular treatment is selected. At the time of angiography, left main coronary artery patency can be evaluated via intravenous ultrasonography. In turn, this could aid in choosing the optimal treatment, thus saving patients from unnecessary angioplasty or surgery and assisting in the improvement of clinical outcomes after interventions.

\section{Declaration of conflicting interests}

The authors declared no conflicts of interest with respect to the authorship and/or publication of this article.

\section{Funding}

The authors received no financial support for the research and/or authorship of this article.

\section{REFERENCES}

1. Akpınar I, Sayın MR, Karabag T, Küçük E, Dogan SM, Büyükates $M$, et al. Left main coronary dissection in a patient with Takayasu's Arteritis. Turk J Rheumatol 2013;28:47-50

2. Rav-Acha M, Plot L, Peled N, Amital H. Coronary involvement in Takayasu's arteritis. Autoimmun Rev 2007;6:566-71.

3. Nienaber CA, von Kodolitsch Y, Nicolas V, Siglow V, Piepho A, Brockhoff $\mathrm{C}$, et al. The diagnosis of thoracic aortic dissection by noninvasive imaging procedures. N Engl J Med 1993;328:1-9.

4. Manuchehry A, Fontana GP, Gurudevan S, Marchevsky AM, Siegel RJ. Missed diagnosis of limited ascending aortic dissection by multiple imaging modalities leading to fatal cardiac tamponade and aortic rupture. Echocardiography 2011;28:E187-90.

5. Soyuöz A, Isık M, Dogan I, Kılıç L, Kiraz S. Retroperitoneal fibrosis and aortitis as the initial findings of systemic lupus erythematosus. Turk J Rheumatol 2011;26:262-4. 